\title{
Oral Manifestations of Poisons in View of Forensic Odontology-A Review
}

\author{
Abirami Arthanari ${ }^{1}$, Nagabhushana Doggalli ${ }^{2}$, Arun M. ${ }^{3}$, Smitha Rani ${ }^{4}$ \\ ${ }^{1}$ Lecturer in Saveetha Dental College and Hospital, Chennai, Tamilnadu, India, ${ }^{2}$ Reader, Department of Forensic \\ Odontology, JSSDCH, Mysuru, Karnataka-570015, ${ }^{3}$ Professor and HOD, Department of Forensic Medicine and \\ Toxicology, JSSMCH, ${ }^{4}$ Assistant Professor, Department of Forensic Medicine and Toxicology, JSSMCH
}

\begin{abstract}
The aim of this article is to provide an overall view of the literature available about "Poisons" and changes in oral cavity due to poisons. "Oral Cavity" is the first source to identify or analyze the poisonous features and different manifestations observed in postmortem. "Forensic Odontologists" here plays a major role to provide the oral manifestations and diagnosis. The oral cavity can be considered as a region with tremendous potential especially in regard to coming to a final forensic diagnosis. This article revolves around this concept and reviews the different manifestations in the oral cavity observed in post mortem.
\end{abstract}

Keywords: Poisons, Oral Cavity and Oral Manifestation, Forensic Odontologist.

\section{Introduction}

In the field of Forensic the most challenging one is the poison cases. Oral cavity is the major insight for poison consumed cases because it is easy to analyze which type of poison by using the color changes. So, here we are trying to explain the poisons and oral manifestations (ie) clinical or autopsy changes in oral cavity. Law has not tried to define death. The death, in Black's law dictionary means "cessation of life" or "ceasing to exist." Medico-legally, death is defined as permanent and irreversible cessation of functions of the three interlinked vital. ${ }^{[1]}$ Oral cavity can be describedas a window to changes occurring in the human body;almost all systemic variations show manifestationsorally. ${ }^{[2]}$

\section{Various Sources of Poisons in India:}

1. Domestic or household sources: Detergents, disinfectants, antiseptics, insecticides, rodenticides, etc.

\section{Corresponding Author:}

\section{Dr. Nagabhushana Doggalli}

Reader, Department of Forensic Odontology, JSSDCH, Mysuru, Karnataka-570015

e-mail: dr.nagabhushand@jssuni.edu.in

Mobile: 9844413396
2. Agricultural and horticultural sources: Different pesticides, fungicides, and weed killers.

3. Industrial sources: In factories, where poisons are manufactured or poisons are produced as by products.

4. Commercial sources: From distribution centers, and selling shops.

5. From uses as drugs and medicines: Due to wrong medication, overmedication, and abuse of drugs.

6. Food and drink: Contamination in a way of use of preservatives of food grains or other food material, additives such as coloring and odoring agents or other accidental contamination of food and drink.

7. Miscellaneous sources: Snakes bite poisoning, city smoke, sewer gas poisoning, etc. ${ }^{[3]}$

Classification of Poisons: Poison may be classified in several method, following are 2 sorts during which poison may be classified:

\section{Chemical}

Inorganic

(a) Corrosives

(b) Metallic and non-metallic salts 


\section{Organic}

(a) Volatile

(b) Non-volatile, non-alkaloidal

(c) Alkaloidal

\section{II)Physiological/pharmacological}

\section{Corrosive}

(a) Strong mineral/organic acids

(b) Strong alkalis

\section{Irritant}

(a) Metallic

(b) Vegetable

(c) $\operatorname{Gas}^{[4]}$

Commonly Used Poisons in India: Suicidal (KCN, HCL, opium, barbiturates, Organophosphorus), homicidal (arsenic, aconite, thallium, oleander, madar, carbamates). Pesticides are commonly used for self-poisoning. ${ }^{5]}$ Pesticides are highly toxic and poisoning may be a significant problem in India. ${ }^{[6]}$ In parts of Northern India, aluminum phosphide (AlP) causes most deaths. ${ }^{[7]}$

Organophosphorus Compund and its Oral Manifestations: Organophosphorus compunds are the overall name for any compound containing phosphorus. OP compounds are widely used for a couple of decades in agriculture for crop protection, pest control \& additionally, in veterinary, medical uses and "nerve gases" in chemical operations.

\section{Classification of organophosphorus compounds:}

According to their toxicity and clinical use OP compounds are classified as:

1. Highly toxic OPs: Agricultural insecticides.

2. Intermediately toxic OPs: Animal insecticides.

3. Low toxicity: Household application and also in field applications. ${ }^{(8)}$

Most OPs are highly lipid-soluble agents and are well absorbed from the skin, oral mucous membranes, conjunctiva. ${ }^{(9)}$

Clinical Manifestation: The onset and severity of

symptoms of organophosphate depend upon the precise compound, amount, route of exposure, and rate of metabolic degradation. ${ }^{(7)} \mathrm{A}$ person's can are available contact with OP by various means like ingestion, eating or drinking, inhalation or dermal contact. ${ }^{(10)}$

Oral Manifestation of OP Poisoning: Most OPs are highly lipid soluble compounds and well absorbed from intact skin, oral mucous membranes, conjunctiva. Most characteristic garlic smell from the mouth. ${ }^{(7)}$

AlP (Phostoxin, Fumitoxin) And Its Oral Manifestation: AlP is an compound, which is usually used as a fumigant since 1940. it's utilized for control of pests in buildings (structural fumigation) and also used during processing of products to be imported or exported to stop transfer of exotic organisms. ${ }^{(11)} \mathrm{AlP}$ when ingested, liberates of Phosphine gas within the stomach, which features a very pungent smell. ${ }^{[12]}$

Symptoms of more severe toxicity includes: ${ }^{[13,14]}$ Individuals after death consuming ALP on external examination during autopsy, face when observed appears to be livid or distinct bluish discoloration. Garlicky pungent odor are often noted in many cases. Froth are often noted round the mouth and/or nose. ${ }^{[15,16]}$

Lead Poisoning: Lead $(\mathrm{Pb})$ may be a soft, ductile, bluishgray metal that's extracted chiefly from galena. Additionally on mouth, it causes astringency \& metallic taste. Chronic plumbism results when small amounts of lead are taken in over a extended period. ${ }^{[7]}$

Oral Manifestation of Lead Poisoning: A "lead hue" of skin with pallor is another feature. A blue line along the gum, with bluish black edging to the teeth is another indication of chronic plumbis. Fig: $1 \& 2^{(17,18)}$

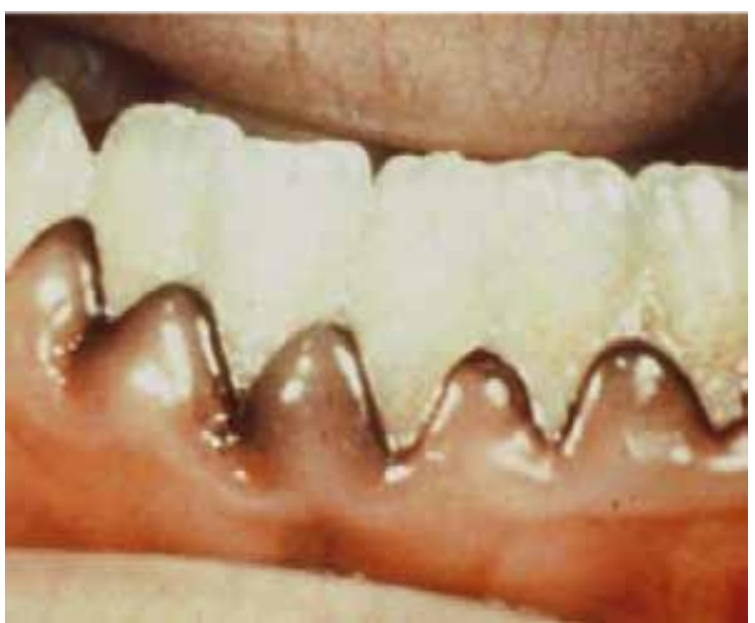

Fig: 1 Shows gingival enlargement 


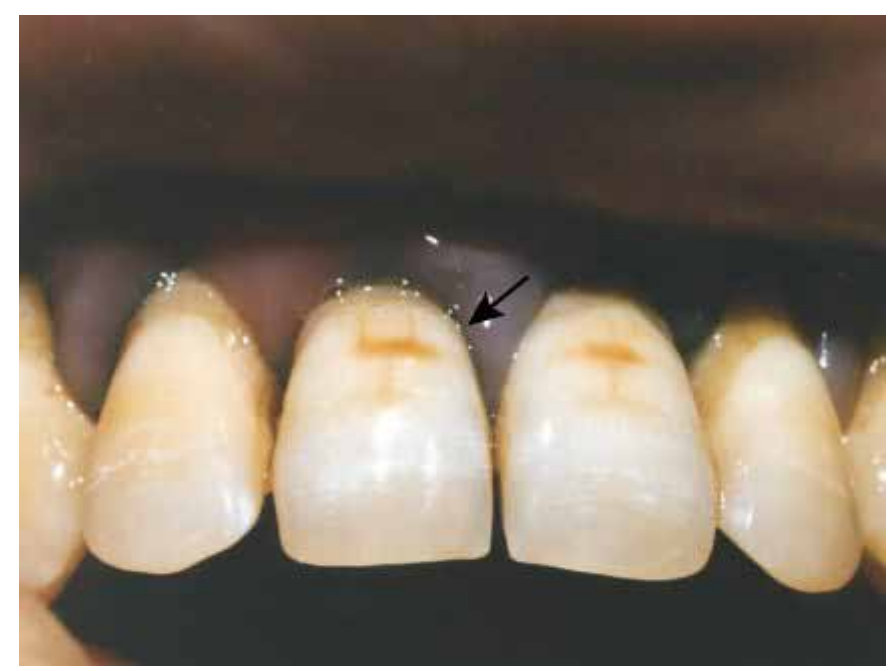

Fig: 2 Shows Blue Colour Discolouration (Lead Line)

Arsenic Poisoning and Its Oral Manifestation: Arsenic may be a element that happens in many minerals, mainly combined with sulfur and metals, also it's commonly used as a semiconductor. ${ }^{[19]}$

Oral Manifestation of Arsenic Poisoning: Groundwater contamination by arsenic is a major public health concern worldwide. Chronic exposure to arsenic cause various types of skin lesions including raindrop pigmentation, hyper-pigmentation, hyperkeratosis, squamous cell carcinoma, basal cell carcinoma, and Bowen's disease.

Signs and symptoms are also found on other tissues of the body including the tongue, gingival, and buccal mucosa. ${ }^{[15]}$ Toxic metals have profound effects on oral health. Melanocytes present in the basal cell layer of the oral mucosa are similar to those found in the skin. ${ }^{[20]}$ The changes are shown (fig 3).

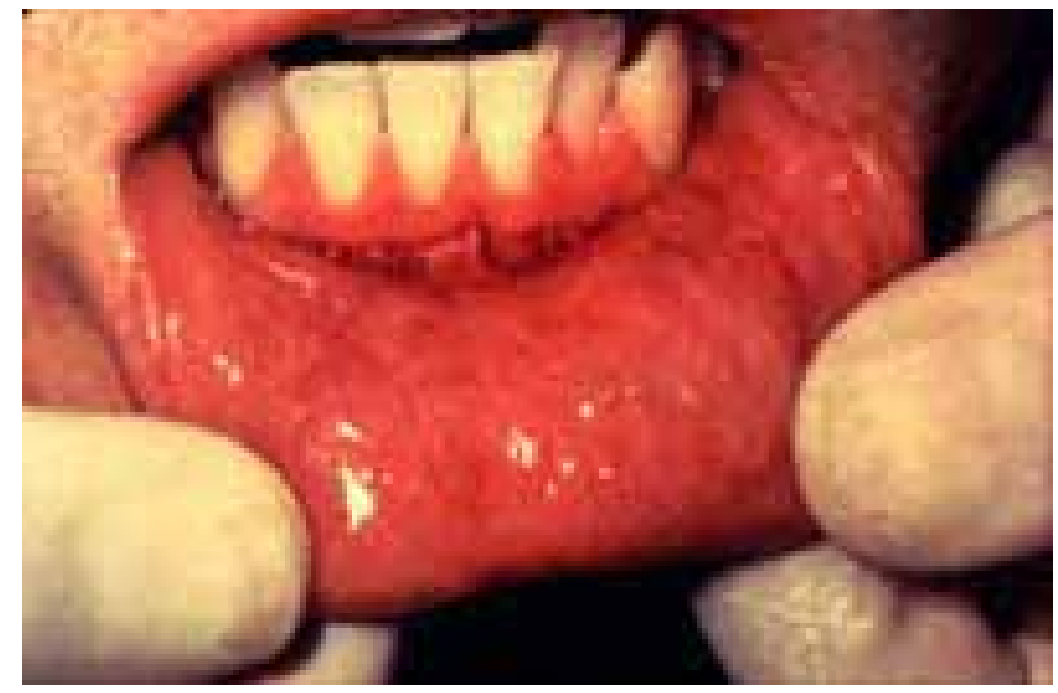

Fig 3: Shows the Rain drop pigmentation, hyper pigmentation, etc.,

Boric Acid Poisoning and its Oral Manifestation: Boric acid (BA) is an odorless compound (H3BO3; $5.5 \%$ Boron) which can be used as pesticide, water softener and personal care products such as toothpastes $\&$ disinfectant. It is also used in high concentrations as pesticide ( $99 \%$ boric acid). ${ }^{[21 \& 22]}$ 


\section{External Oral And General Manifestation of Boric Acid Poisoning:}

1. At first glance, intense cyanosis of lips and nail beds were evident

2. Inflammatory changes in oral cavity and brownish stains along with right angle of mouth and right nostril.. ${ }^{[23]}$

\section{Sulphuric Acid Poisoning and its Oral} Manifestations: Sulfuric acid is one of the most widely used industrial chemicals. Sulfuric acid is widely used in electrical industry, chemical laboratories, jewelery, and agriculture. The commonest means of intoxication usually takes place through ingestion, acidic vapors are strong irritants to the respiratory mucosa and may cause pulmonary edema in the more severe cases. ${ }^{[24]}$

Oral Manifestation of sulphuric poisoning:

Insensitive yellowish spongy tongue, gums, buccal mucosa, and palate. ${ }^{[24]}$

\section{CASE REPORT OF POISONING AND ORAL} MANIFESTATIONS:

\section{Case 1- Organophosphorous Poisoning:}

The first subject was a moderately built, male with approximate age ranging from 30-32 years. Presence of white froth observed in corners of mouth $\&$ nose. The eyes characteristic hazy presentation also referred to as glassy appearance. Examination of oral cavity revealed thickening of the oral mucous membranes with mild whitish discoloration, and moderate tointense white discoloration with the attached gingival. The tongue also displayed white patches. (fig 4). ${ }^{(2)}$

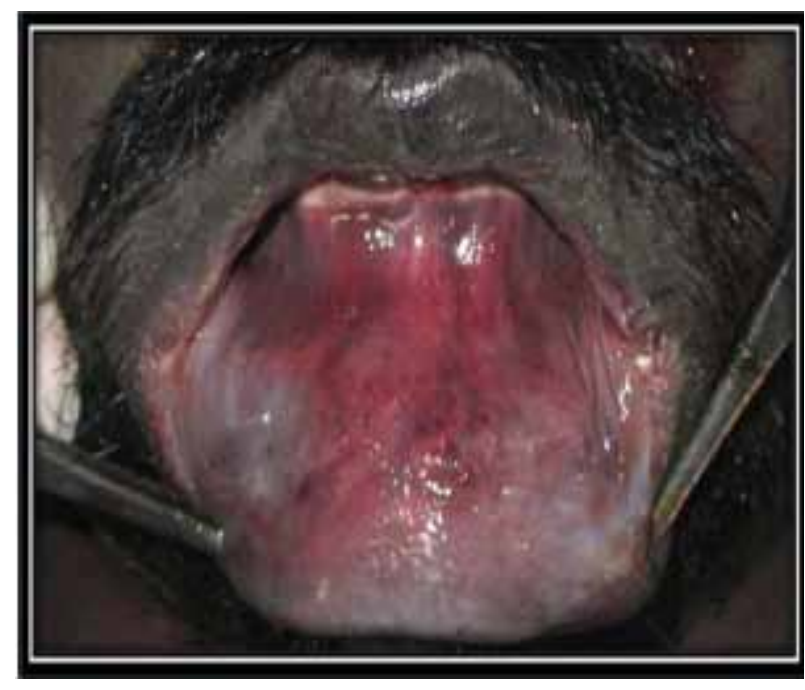

Fig 4: Oral manifestations in the case of organophosphorus poisoning

After the Chemical analysis it revealed the cause of death is to be ingestion of organophosphorus compound. [25]

This has three types of effects: (1) muscarinic, (2) nicotinic, and (3) central effects. ${ }^{[26]}$

\section{Case 2: Sulphuric Acid Poisoning:}

A 36-year-old jeweler was admitted to our emergency department 30 minutes after he accidentally ingested highly concentrated solution of sulfuric acid. He suffered immediate cutaneous burns of varying extent and depth on his face,neck, thorax, and abdomen. He had a severe trismus with insensitive yellowish spongy tongue, gums, buccal mucosa, and palate (Fig. 5). ${ }^{[24]}$

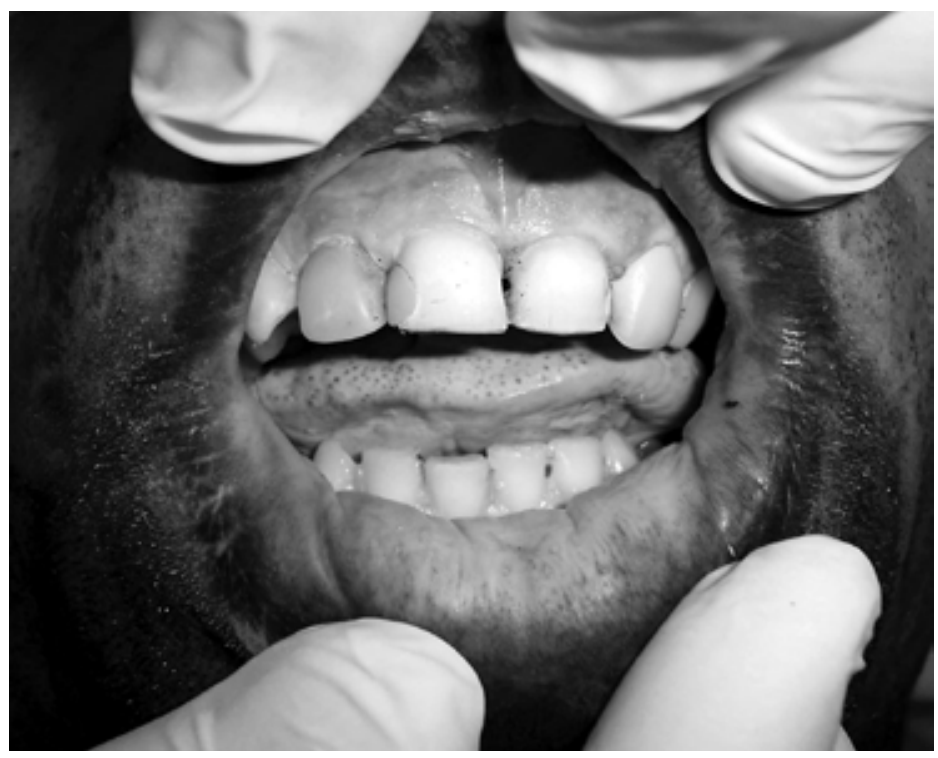

Fig 5: The necrosis of the lips, tongue, and gums is evident.

Case 3: Sulphuric Acid Poisoning:

The second subject was a moderately built female,approximately 17-20 years of age. Various patchesexhibiting yellowish discoloration were also present allover the body. Darkening of the skin was observed from the facialregion extending till the neck. Swelling of lips was presented along with signs of cyanosis.

Examination ofthe oral cavity revealed a faint generalized yellowishtinge with the oral mucosa; the teeth exhibited anunusually white shade and were 
brittle in consistency (fig 6). There was moderateto intense yellowish discoloration of the tongue seen. The chemical analysis in this caseshowed the cause of death to be sulphuric acidpoisoning. ${ }^{[2]}$

The injuries in mouth, throat, esophagus, reversible or irreversible. The damaged mucous membrane, the sub-mucus regenerate only with great difficultybecause of the surrounding inflammation andsecondary complications ${ }^{[27]}$ Naik SM et al (2012)reported a case of acute accidental formic acidpoisoning and examination of oral cavity revealedintense corrosion of tongue and the oralmucosa. ${ }^{[28]}$ Vijanath Vet al (2010) presented a suicide case, consumption of sulphuric acid and theautopsy revealed extensive demarcated cutaneousburns on the inner aspect of the lips. ${ }^{[29]}$

In a study performed by MalcolD (1961) on the effect of sulphuric acid on the teeth ofbattery workers observed the initial lesion to be etchingof the labial surface of the enamel, giving a dullground glass appearance barely visible nakedeye. The exposed surface of teeth were highly polishedor etched \& also said that both material alba andcalculus dissolved completely from the exposedsurfaces in vivo, which shows false presentation of goodoral hygiene. ${ }^{[30]}$

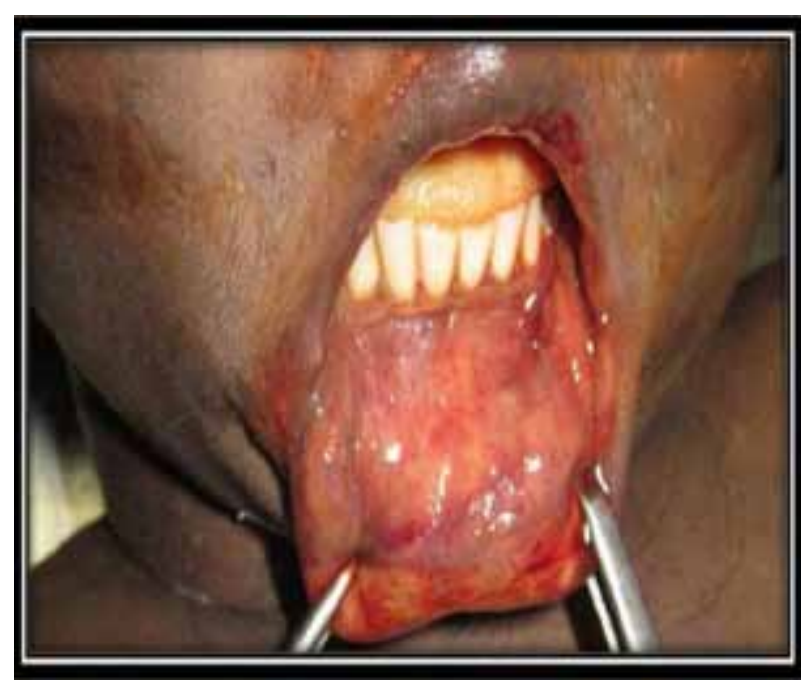

Fig 6: Oral manifestations in the case of sulphuric acid poisoning

Case 4: Rodenticide, Aluminium phosphide, Battery acid:

An automobile mechanic with an alleged history of consumptionof rat killer poison mixed with battery acidpresented with coffee coloredin oral cavities. Clinical examination at our hospital revealed congestion and ulceration of the oral. At autopsy erosions and minute haemorrhages wereseen on both lips and dorsal aspect of the tongue. ${ }^{[31]}$

\section{SNAKES POISONS AND ITS ORAL MANIFESTATIONS:}

Deaths due to bite/sting of a venomous animal accounted for $10.7 \%$ of all deaths due to unintentional injuries, with an adjusted mortality rate of 6.2 (95\% CI $6.0 \pm 6.3$ ) per 100,000 population. By seeing the oral manifestations we can judge and conclude the snake bite.

\section{Oral Manifestations:}

Spontaneous systemic haemorrhage is most often detected in the gingival sulci. Later the face, palate, jaws, tongue, vocal cords, neck muscles become paralysed, Locally Froath formation and Bluish or Blackish discolouration of oral cavity and face. ${ }^{(34)}$

\section{CASE REPORT OF SNAKE BITE:}

\section{Case report 5: 14 years/girl, Respondent: Brother}

Brother of the deceased told that his sister had slept at night after dinner. After sometime, someone went to check on her but she was found dead. Her whole body hadturned pale and froth was coming from her mouth. Because of the froth, they came to know that a snake had bitten her.

\section{SUMMARY:}

A general review of this literature showed us many cases with documented post-mortem oral manifestations. The oral cavity can be considered as a region with tremendous untapped potential especially in regard to coming to a final forensic diagnosis, but this aspect of forensic medicine is relatively undiscovered and overlooked. The above cases shed light on the prospects offered by observation of the manifestations of the oral cavity post mortem and their significance in the field of forensic science. ${ }^{[2]}$

Organophosphorus insecticides appearto be the most commonly ingested pesticides in ruralAsia, accounting for around two thirds of cases. ${ }^{[32]}$ Organophosphorus poisoning; after hanging (49\%) isknown to be the second most common method ofsuicide in India $(40.3 \%)$. ${ }^{[33]}$

Findings from arsenic poisoning suggest that a higher level of urinary arsenic concentration isassociated with higher risk of arsenical lesions of gums \& tongue. 
In the present review, we provide further direct evidence that arsenichas stronger association with arsenicosis symptoms of gums \& tongue. These findings imply that contamination of drinking water with arsenic might alsobe a risk factor for arsenicosis of the gums and tongue. ${ }^{[20]}$

A dead body witherythematous rash, redness of skin, bluish green color ofvomitus and fecal matter, corrosive changes in oral \& nasal cavity \& multiple organ damages can be highly suggestive of Boric Acid poisoning. ${ }^{[23]}$ Sulfuric acid is widely used in electrical industry, chemical laboratories, \&agriculture. ${ }^{[24]}$

\section{Conclusion}

The main aim of forensic toxicology is that the technology and therefore the techniques that are utilized in obtaining and interpreting the results. The explanation for death could also be achieved after considering all the forensic investigations. The aim of this paper was to report the likelihood of poisoning and the way to interpret the oral manifestation (ie) (Oral Cavity Changes) in perfumes and other household products which will contain this substance.

Ethical Clearance: It is just a review article. It does not come under any ethical review.

\section{Source of Funding: Self}

\section{Conflict of Interest: Nil}

\section{References}

1. Nandy A. Principles of forensic medicine. 3rd ed. Calcutta: New central book agency (p) ltd; 2005.

2. Sneha Sethi, Poonam Goel, Sonam Bhalla, Oral Cavity: An insight to forensic diagnosis, Asian Pacific Journal. Health Sci, 2015;2(2):142-147.

3. Sabri I. Forensic toxicology: General consideration. J.N. Medical College. Tuesday, December 21, 2010, 2:18:58 PM.

4. Available from:http://webcache.googleusercontent. com Tuesday, December 21, 2019, 2:21:16 PM.

5. Eddleston M, Phillips MR. Self poisoning with pesticides. BMJ 2004;328:42-4.

6. Srinivas Rao Ch, Venkateswarlu V, Surender T, Eddleston M, Buckley NA. Pesticide poisoning in south India: Opportunities for prevention and improved medical management. Trop Med Int Health 2005; 10:581-8.
7. Charan Gowda B.K, Sivapatha Sundhatam B, Jypthi Mahadesh, Mukund. Oral Toxicology Journal of Forensic Dental Sciences, January - June 2014/vol 6/issue 1

8. Joshi S, Biswas B, Malla G. Management of organophosphorus poisoning. Available

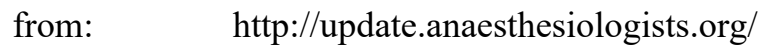
wp-Organophosphorus-Poisoning.pdf. Tuesday, December 21,2019, 10:10:44 AM.

9. Available from: http://curriculum.toxicology. wikispaces.net/2.2.7 .4.5+Organophosphateshttp:// curriculum.toxi cology.wikis paces . net/2.2.7.4.5+Organophosphates. Tuesday, December 21, 2019, 9:52:42 AM.

10. Available from: http://www.idph.state.il.us/ Bioterrorism/factsheets/organophosphate.htm. Wednesday, December 22, 2019, 10:22:08 AM.

11. Available from: http://en.wikipedia.org/wiki/ Aluminium_phosphide. Wednesday, February 02, 2020, 11:04:12 AM.

12. Kumar L. Available from: http://www. associatedcontent.com/. Wednesday, February 02, 2020, 11:31:38 AM.

13. Available from: http://pmep.cce.cornell. edu/profiles/extoxnet/24d-captan/ aluminum-phosphide-ext.html. Wednesday, February 02, 2020, 2:47:54 PM.

14. Jain AK, Nigam M, Garg SD, Dubey BP, Arora A. Aluminium phosphide poisoning autopsy findings. JIAFM 2005;27:???. ISSN 0971-0973.

15. Available from: http://en.wikipedia.org/wiki/ Lead_poisoning\#cite_note-Andrews-23. Tuesday, December 07, 2019, 2:18:02 PM.

16. Marcus S. Available from: http://emedicine. medscape.com/article/815399-overview. Tuesday, December 07, 2019, 2:11:54 PM.

17. Link is here

18. Link is here

19. Available from: http://en.wikipedia.org/wiki/ Arsenic_poisoning. Tuesday, December 07, 2019, 12:03:08 PM.

20. Emdadul H. Syed, PhD, Stephanie Melkonian, MS, Krishna C. Poudel, PhD, Junko Yasuoka, $\mathrm{PhD}$, et al., Arsenic Exposure and Oral Cavity Lesions in Bangladesh,J Occup Environ Med. 2013 January; 55(1): 59-66. doi:10.1097/ JOM.0b013e31826bb686. 
21. Wax PM. Antiseptics, Disinfectants, and Sterilants. In: Nelson LS, Lewin NA, Howland MA, Hoffman RS, Goldfrank LR, Flomenbaum NE, editors. Goldfrank's Toxicologic Emergencies. 9th ed. New York: McGraw-Hill; 2011. p.1345- 57.

22. Litovitz TL, Klein-Schwartz W, Oderda GM, Schmitz BF. Clinical manifestations of toxicity in a series of 784 boric acid ingestions. Am J Emerg Med 1988 May;6(3):209-13.

23. MUKTA RANI, MAHESH CHAND MEENA, Multiple Organ Damage Due to Boric Acid Toxicity, Asia Pac J Med Toxicol 2013;2:157-9

24. Rony Aouad, MD, Nayla Matar, MD, Antoine Melkane, MD, Michel Nassar, Sulfuric Acid Ingestion, The Journal of TRAUMA ${ }^{\circledR}$ Injury, Infection, and Critical Care • Volume 70, Number 5, May 2011

25. Vijayanath V, Raju GM, Rao KN and Anitha MR. Suicidal Acid injury; a case report. J Indian Acad Forensic Med 2010;32(4):347-348.

26. Wadia RS, Sadagopan C, Amin RB and Sardesai HV. Neurological manifestations of organophosphorus insecticide poisoning. J Neurol Neurosurg Psychiatry 1974 July;37(7):841-847.

27. Cibisev A, Nikolova-Todorova Z, Bozinovska C, Petrovski D and Spasovski G. Epidemiology of severe poisonings caused by ingestion of caustic substances. Contributions Sec Biol Med Sci 2007;28(2):171-183.
28. Naik SM, Ravishankara S, Appaji MK, Goutham MK, Devi NP, Mushannavar AP et al. Acute accidental formic acid poisoning: a common problem reported in rubber plantations in Sulia. Int J Head Neck Surg 2012;3(2):101-105.

29. Vijayanath V, Raju GM, Rao KN and Anitha MR. Suicidal Acid injury; a case report. J Indian Acad Forensic Med 2010;32(4):347-348.

30. Malcol D and Paul E. Erosion of the teeth due to sulphuric acid in the battery industry. Brit J Industr Med 1961;18(6):63-69.

31. Nisreen Abdul Rahman, Siddhartha Das, Vinod Ashok Chaudhari et al., Blending of rodenticide and battery acid - a rare and fatal suicide mix, Egyptian Journal of Forensic Sciences (2017) 7:8

32. Gunnel D, Eddleston M, Phillips MR and Konradsen F. The global distribution of fatal pesticides selfpoisoning: Systematic review. BMC Public Health 2007;7(357):1-15.

33. Aktar WA, Sengupta D and Chowdhury A. Impact of pesticides use in agriculture: their benefits and hazards. Interdiscip Toxicol 2009 March;2(1):112.

34. Mehta SR, VSM, Sashidran VK Clinical Features And Management of Snake Bite, Med J Armed Forces India. $2002 \mathrm{Jul} ; 58(3)$ : 247 to 249. 